\title{
"A painted picture which never captures the subject" Sharon Kivland \& Jeanne Randolph: A Repartée on Psychoanalysis and Art
}

\author{
Edited by Cheryl Sourkes
}

Sharon Kivland est une artiste et curateure du Centre pour l'analyse et la recherche freudienne à Londres, Angleterre. Jeanne Randolph est une psychanalyste torontoise et auteure du livre La symbolisation et ses mécontentements. Ce qui suit est un extrait tiré d'une discussion publique entre les deux femmes sur leurs relations à la théorie psychanalytique et la relation entre la psychanalyse et la pratique artistique. L'événement a été organisé pour coïncider avec l'exposition photo Mes tendresses (or, My Endearments) de Sharon Kivland lors du Toronto Photographers' Workshop en janvier 1998. La répartie est éditée par Cheryl Sourkes.

Sharon Kioland is an artist and curator at the Centre for Freudian Analysis and Research in London, England. Jeanne Randolph is a Toronto psychotherapist and the author of Symbolization and its Discontents. The following is an excerpt from a public discussion between these two women about their relationships to psychoanalytic theory, and the relationship between psychoanalysis and art practice. The event was staged to coincide with the opening of Kivland's photographic exhibition, Mes Tendresses (or, My Endearments) at the Toronto Photographers' Workshop in January 1998. The repartee is edited by Cheryl Sourkes.

The photos, glass and metal, the materiality of the work, function metaphorically to suggest a range of perceptual possibilities: transmission, reflection and blindness. The viewer finds herself reflected in the images. Transmission becomes confused by mirroring; implication enters the body of the image and becomes blindness.

-Cheryl Sourkes, "What Pictures Want," exhibition catalogue for Sharon Kivland, Mes Tendresses (or, My Endearments), TPW, 1998.

JR: Don't you think that each of us should let the audience know what we mean by psychoanalysis or psychoanalytic theory since it's in our titlethat it would be fair to kind of position ourselves. 
SK: Well, there are two kinds of psychoanalysis. I'm from England and there's a thing called psycho-analysis that's written "psycho-dash-analysis." It's the British psycho-analytic establishment and it's distinguished by its hyphen. [laughter] It's got nothing to do with the kind of psychoanalysis I'm interested in, which has lost its hyphen. What I mean by psychoanalysis, is Lacanian psychoanalysis. Actually $80 \%$ of practicing psychoanalysts are Lacanian, certainly within South America and in certain parts of Europe. Some parts of Europe are psycho-hyphen-analysis which is something to do with ego psychology. Most of North America is psycho-analysis. We hold Barcelona, psycho-hyphen-analysis holds Madrid. These are battlegrounds.

Psychoanalysis without the hyphen, the Lacanian psychoanalysis is subject to schism as well. In London, it's subject to schism between two groups: the London Circle and the Centre for Freudian Analysis and Research. I work for the Centre for Freudian Analysis and Research. I'm their curator. However, the London Circle is also comprised of people who belong to the Centre for Freudian Analysis and Research. It's not a training group but it could be a training group so something that I call psychoanalysis without the hyphen may very shortly be subject to some kind of hyphenation. [laughter]

JR: You know I have to relate to this word "hyphenation" because I feel that for the last twenty years what I've been trying to do is hyphenate myself. And I thought, "how would I position myself in regard to psychoanalytic theory, finally come out of denial and admit to everyone here, yes, I really am a practicing psychotherapist"? And how would I talk about psychoanalytic theory, not only as a construction or a medium I work in which I like to fiddle with, which I like to press, which I like to change to suit my own willful purposes, but also to talk about where I am in relation to psychoanalysis or psychoanalytic theory subjectively, given the fact that $I^{\prime} m$ supposed to actually be helping people who are in pain and who are complex, living, changing beings and yet, supposedly, something that is so rhetorical and something that is so theoretical as psychoanalytic theory is supposed to overlap with some of my experiences with the people who come to me for help. I think that in some sense my interest has been in proving that the theory is a kind of painted picture which never captures the subject, that is, the person who is in pain and asking for help. And I think that as an art writer and someone who is trying to distort theorywhat I'd like to do is to make something creative or something that contributes to culture out of the dilemma of psychoanalytic theory in some sense being pathetic or inadequate or thin or pretty skimpy. I would think of psychoanalytic theory as a bikini. [laughter] 
SK: Psychoanalysis is this bikini thing. It doesn't cover anything adequately. But I don't think that's an inadequacy within psychoanalysis. The impulse then must be for psychoanalysis to define itself much more clearly, to make obvious what it is.

JR: Right. Would you say in some sense that is your project, that you can illuminate that process by an art practice? Would you say that some of your works or some of your writing illustrates that, or illuminates that or exemplifies it?

SK: I would hope that it neither illustrates it nor exemplifies it because it becomes a merely didactic process. It's not a teaching aid. My work isn't a teaching aid to doing psychoanalysis any more than it would be a teaching aid to doing art or doing culture.

JR: So is there a word for it if it's not exemplify?

SK: I haven't found a word or a place for it. It goes alongside it. It's part of a practice that includes something of psychoanalysis but at the same time doesn't attempt to illustrate it. Though occasionally I find myself producing things that resemble nothing more than Lacanian teaching aids.

JR: What's your reaction when that happens?

SK: Delight because it seems a kind of ironic mode of production. The particular thing I'm thinking of is an elegant gray silk box, it slides open like a little drawer, and it's embossed with the word l'imaginaire. When you open it there's a slightly tasteless pink silk interior in which nestles a little silver compact. The compact has two mirrors, base and top. In the bottom mirror is engraved the word moi, but upside down and back to front, which only becomes readable in the top part of the mirror. And the whole structure reveals itself as one of the imaginary. It's something that worked out as a way of talking about what the imaginary relation to oneself as a subject is, the reflection in the mirror, the me that is fragmented, subject to coming apart, permanently, continuously threatened by fragmentation that in the mirror image becomes whole.

JR: Now is that autobiographical?

SK: Well, we all go through some structural stage when we assemble ourselves in the mirror according to our image. It's the time we become a speaking subject, the time we start to have a relation with language. There I am-over there. No longer at one with myself. The difference between I and me. You cite Winnicott and Winnicott is very clear on that. Maybe the 
difference between Winnicott and Lacan with relation to the mirror stage is that for Winnicott it's the mother who offers the mirror, the mother who is the guarantor and for Lacan, the mother is not a guarantor; she's the thing that can't be controlled in the mirror.

JR: I think Winnicott's theory is suspect in that regard. Winnicott speaks of the maternal environment as a totalizing environment and that we read ourselves in our mothers. And I worry that he's so literal about that, and that therefore the implication for the artist is almost as if one were endlessly repeating that the art object is your 'made' mother...

SK: Your reparation as well, which goes back to Melanie Klein doesn't it. This restoration that can be effected; the damage that you've inflicted upon the maternal body of the child can be repaired.

JR: Don't you think that reduces it somehow?

SK: Of course. Adrian Stokes, the art historian, talks about architecture as a form of reparation, that every time a modernist architect is building a building, he's repairing the damaged body of the mother. It's ludicrous!

JR: But it could be so ludicrous that there could be some kind of psychotic grain of truth in it.

SK: Well, it depends upon which architects you're talking about. [laughter]

JR: I wanted to be sure that people understood what we meant by psychoanalytic theory or what we meant by psychoanalysis or where we positioned ourselves.

SK: Just a minute Jeanne, I haven't finished. Psychoanalysis and psychoanalytic theory do have a difference. They're not the same thing. When you're in psychoanalysis, you're not doing psychoanalytic theory. You have to leave that behind you. Theory is the very thing that you have to leave at the door.

JR: But as the analyst, you can't leave it at the door.

SK: Well if you left it at the door you would be in a problem with the analysand, but the analysand can't come in speaking theory. What the analyst wants to do, the ethical duty of the analyst is to get the analysand speaking; not only speaking but speaking well. Because the analysand comes as a semantic failure, someone who knows something but has no 
words with which to say it. So they go to the analyst to learn how to speak the words and it's never the words they imagined would be spoken. The words that are spoken, the full speech, the truthful speech are not the words of theory so there the analyst has to work against theory. The analysand comes to a relationship with analysis because of something of an imaginary relation, that there is something about that other that makes that other the one who's supposed to know. But what the analyst does is put him or herself in the place of the object, not of the master, not of the other, but the object.

JR: I think that what's interesting to me when I am a reader or a gallerygoer or someone who has an artwork in my house, what interests me is that there are certain things I wish were true. It's the arousal of that wish that something were true that I'm so interested in. I wasn't sure where you stand on the issue of autobiography. Is it a theoretical question for you? Is it an abstract notion? Is it something you put in your work in a very coded way? Or is it something that you don't feel is actually an issue for art, at this point for you.

SK: I imagine, that there is no narrative of self-biography there whatsoever. That's my fantasy about it. I've got no way of establishing my relation to that at all, but my strategies are always those of distancing from any revelations. The work is not synonymous with me. The work continues to do or not do what it does or doesn't do irregardless of my intentionality.

JR: Would you say in a sense that as you've matured as an artist that you've developed the ability to create that distance or that non-autobiographical effect on the audience? Would you say that there's been a process of maturing the art work or developing the art work or discovering within the media you use that you can actually hype that up in some way?

SK: There's a greater and greater closure within it, often through the material means of its presentation. And if there's a narrative impulse within it, then that's given over to or directed towards the viewer. We all have the desire to make narratives, but the story that might be pieced together has little if anything to do with any narrative that belongs to me. And I would be horrified if it did. It's almost like the horror one feels when someone starts to tell you about themselves without any stopping them and you're thinking "Get me out of here!" But the interest one feels when someone else comes up and says, "Do you know what is happening to them?" and you listen. You want to hear it, you want to hear it as a mediated account. So it's that I'm trying to capture, the mediated account, the space you can 
listen in without being forced to feel this direct effect on your body.

JR: That certainly is consistent with a lot of things that Winnicott has said about culture and this goes back to projection and the process by which either as writer or as a visual artist we handle the possibility of that kind of projection. And just to review Winnicott's position, the object relations position on that would be that in some sense there's actually a third area of relationship between people, that the culture actually creates an area in which you talk by proxy. You talk or you communicate by both contributing to a phenomenon that's not either of you. So in that sense your art work is, in a way, something that people could gossip about and could converse about and could create an experience about, but the art work's not interrogating them on its own, or spilling the beans on its own. That's a very Winnicottian position. I don't know how or where it fits in with Lacanian theory.

SK: Well, because Lacan changes his thinking about the object, his idea of the object goes from 'object $a$,' the little other, this object cause of desire, to the Freudian thing, to the real, and it ends up as something that fills up the void. This abyss that's caused by lack, the object is something that comes to fill it. It can't fill it for long, it can't block it, but it can come into play for a moment and hold it at bay. So for Lacan, art is an ethical way to the real. To Lacan suicide is an ethical way to the real as well, and so is psychosis...

JR: How terribly French... [laughter]

SK: Well you don't escape your symbolic order ever. [laughter]

JR: So although you're emphasizing the lack aspect that the symbolic attempts to breach, it's really a paradox that the only way to even approximate knowing, understanding, touching, immersion - the only way to even approximate it is symbolization that reaches across the unbreachable gulf.

I have something to react to actually, and this reflects my dilemma not only as a therapist and a Southern belle, but also as a writer, the relationship between becoming more and more expert or having more and more technique so that after awhile you've got to be pretty dumb if you don't know some of the effects you're having. I mean after a while, it's a responsibility to know what sort of effect you're having on the audience.

SK: Well I think you're absolutely right. All I can say is that I've become stupider and stupider about it. I know less and less about it. Earlier, I might have had some idea or wanted to project some idea of audience. I 
might even have imagined that I was speaking to many. Now I know, the one thing I'm sure of, is that I'm only speaking to one other. I don't know who that other is. I don't even know if that other exists. I suspect it's becoming this other, this audience, Lacan's big other, L'Autre with a capital A, something that is outside yourself and at the very same time it is also at the most intimate, interior part of yourself. So at a time when questions of audience perhaps are most important, it's a question that no longer troubles me.

JR: Although there's this possibility or this wish of something that nurtures, there's a sadistic part of me that just loves the idea of actually being rather reptilian and cold-blooded and scary as well. One of the questions I was curious about was your stance on aggression and sadism and a kind of cruelty... it's the insidiousness of the cruelty or the insidiousness of the recognition of evil, the insidiousness of the recognition that at a certain point desire will out. I'm curious what position you've developed in your art work in regard to that. It strikes me that one of the fundamental effects to be dealing with in an audience is whether they feel assaulted or seduced or some combination thereof at the same time.

SK: I think there's something absolutely intrinsic there of a denial. At first glance, something is offered which is not at all offered. So simultaneous to the sense of seduction, of allure, of presentation, there's a turning away, a non-delivery. And the image that comes into mind is of the cruel lady of courtly love who can never be possessed because to possess her would be to stop the chain of desire. So they can't deliver. In order to function they have to promise, to appear to offer something which makes one follow them.

JR: I feel like television and mass culture have kind of short-circuited that in some way. You feel it's intrinsic to the human psyche so there's no way it could be short-circuited?

SK: I think it's part of the signifying chain of language. We can move from one signifier to another signifier, although there have to be points which anchor it, but that's what speech is. It's the moving of desire and desire is standing in all the time, a part for the whole.

JR: "The paradox" I call it, because it also, as your work does, both promises and denies. 